\title{
Beauty is in the eye of the beholder: Cruciform eye reveals new species of direct-developing frog (Strabomantidae, Pristimantis) in the Amazonian Andes
}

\author{
Germán Chávez ${ }^{1,2}$, Luis A. García-Ayachi ${ }^{1,2}$, Alessandro Catenazzi ${ }^{1,2,3}$ \\ 1 Instituto Peruano de Herpetología (IPH), Augusto Salazar Bondy 136, Urb. Higuereta, Surco, Lima, Perú \\ 2 División de Herpetología, Centro de Ornitología y Biodiversidad (CORBIDI), Santa Rita No. 105 Of. 202, Urb. Huertos de San Antonio, \\ Surco, Lima, Perú \\ 3 Department of Biological Sciences, Florida International University, 11200 SW $8^{\text {th }}$ St., Miami, FL 33199, USA \\ http://zoobank.org/117AA0B4-99A2-4F4F-85A9-B9FAE8E47BB1 \\ Corresponding author: Germán Chávez (vampflack@yahoo.com)
}

Academic editor: Martin Husemann • Received 27 January 2021 • Accepted 22 March 2021 • Published 9 April 2021

\begin{abstract}
We describe a new species of frog from the eastern slopes of the Andes in central Peru. Pristimantis sira sp. nov. has a distinctive crossing mark on the iris and no tympanum. The new species is closely related to P. antisuyu Catenazzi \& Lehr, 2018, P. cruciocularis Lehr, Lundberg, Aguilar \& von May, 2006, and P. erythroinguinis Catenazzi \& Lehr, 2018, but is easily differentiable by lacking colour blotches on groins. Pristimantis sira sp. nov. inhabits the mountain forests from 1550 to $2200 \mathrm{~m}$ a.s.1., inside a national reserve threatened by illegal mining.
\end{abstract}

\section{Key Words}

Andes, crossing mark, iris, national reserve, illegal mining

\section{Introduction}

Expeditions to remote places in the eastern slopes of the Peruvian Andes have shown that unexplored neotropical mountains are sources of unknown and endemic herpetofauna (Duellman et al. 2014; Catenazzi et al. 2015; Echevarría et al. 2015; Chávez and Catenazzi 2016; Chávez et al. 2017; Lehr and Moravec 2017; Lehr and von May 2017; Lehr et al. 2017a, 2017b). Frogs are one the most diverse herpetofaunal orders, particularly in Andean ecosystems where endemism is high (Swenson et al. 2012). Furthermore, many of the discoveries of new amphibians are frogs (Duellman et al. 2014; Catenazzi et al. 2015; Chávez and Catenazzi 2016; Lehr and Moravec 2017; Lehr and von May 2017; Lehr et al. 2017a, 2017b). Among recently named frogs, most of the new Peruvian Andean species belong to the genus Pristimantis Jiménez de la Espada, 1870, which is the most diverse clade in the Neotropics (Padial et al. 2014). Over the last ten years, herpetologists have named seven new species of Pristimantis from the eastern Andes of central Peru (Shepack et al. 2016; Lehr and Moravec 2017; Lehr and von May 2017; Lehr et al. 2017a, b), showing that these mountains host a still unknown anuran diversity, and that Pristimantis are one of the most diverse clades of these amphibian communities.

El Sira Communal Reserve is located on the eastern slopes of the Andes in central Peru, and protects about 616413 hectares of primary forest. El Sira is the highest cordillera adjacent to the Ucayali River, going from $200 \mathrm{~m}$ to $2200 \mathrm{~m}$ a.s.1., and is bordered by the Pachitea river (which eventually flows into the Ucayali), further isolating the El Sira mountains as the eastern branch of the Andes in the Ucayali basin (see Figure 5). Because 


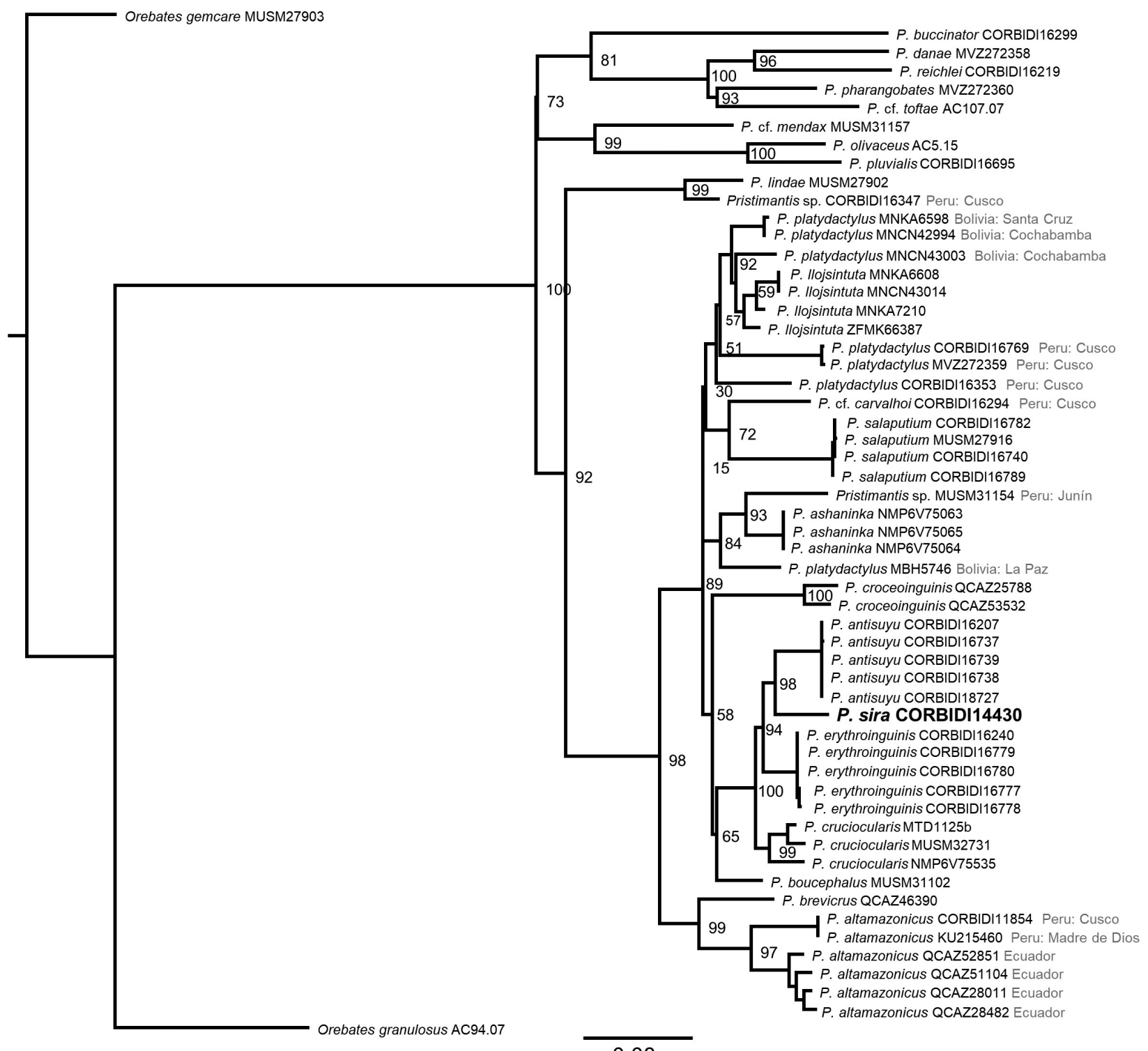

0.08

Figure 1. Phylogenetic analysis based on concatenated dataset of $16 \mathrm{~S}, \mathrm{CO} 1$ and RAG sequences showing the relationship between the new species (highlighted in bold) and its congeners. ML bootstrap values are indicated at each node.

of the hard access and rough topography, El Sira is likely one of the most unexplored places of Peru. Only a handful of herpetological expeditions (Duellman and Toft 1979; Aichinger 1991; Whitworth et al. 2016a, 2016b) have reached these forests, resulting in the description of four anuran species (Duellman and Toft 1979; Aichinger 1991; Lötters and Henzl 2000), all of them endemic from El Sira.

Nevertheless, none of the four endemic frogs described so far is a Pristimantis, in contrast to other mountain chains in Peru where most of the recently described species belong to this genus (Shepack et al. 2016; Lehr and Moravec 2017; Lehr and von May 2017; Lehr et al. 2017a, 2017b). The systematics of Pristimantis is challenging because it often requires an integrative taxonomy approach for species delimitation, and because genetic sequences are not available for many species.
During fieldwork we performed in El Sira Communal Reserve from 2013 to 2014, we collected a series of unidentified Pristimantis frogs. Genetic and morphological analysis revealed that these specimens belong to an unnamed species, which we describe below.

\section{Material and methods}

We follow Lynch and Duellman (1997) for the format of diagnosis and description of the new species. For systematics of Strabomantidae we follow Hedges et al. (2008), Blackburn and Wake (2011) and Padial et al. (2014). We collected specimens during the night while conducting Visual Encounter Surveys (Crump and Scott Jr 1994). We euthanized specimens with an $8 \%$ benzocaine solution, fixed them in $10 \%$ formalin, and stored 
them in $70 \%$ ethanol. We deposited all specimens in the herpetological collection of Centro de Ornitología y Biodiversidad (CORBIDI). The Servicio Nacional de Areas Protegidas de Peru issued collecting permit RJ $\mathrm{N}^{\circ}$ 003-2014-SERNANP-RCS-JEF029-2016-SERFORDGGSPFFS. We measured the following variables to the nearest $0.1 \mathrm{~mm}$ with digital callipers under a stereoscope, as described in Duellman and Lehr (2009): snout-vent length (SVL); eye-nostril distance (E-N); head length (HL); head width (HW); interorbital distance (IOD); internarial distance (IND); tibia length (TL); foot length $(\mathrm{FL})$; eye diameter (ED); upper eyelid width (EW). Fingers and toes are numbered preaxially to postaxially from I-IV and I-V respectively. We determined comparative lengths of toes III and V by adpressing both toes against Toe IV; lengths of fingers I and II were determined by adpressing the fingers against each other. Specimens were sexed based on external sexual characteristics (e.g., presence of vocal sacs in males), and internal dissection of the gonads. Photographs were taken in the field by GC, and in the laboratory by LAGA. We used these photos for descriptions of coloration in life and in preserved condition, respectively. In addition to the type series of the new species, we examined specimens of related congeners (Suppl. material 1) or obtained morphological data from the original description for diagnostic comparisons.

We performed phylogenetic analyses on a concatenated dataset of fragments of two mitochondrial genes (16S rRNA and cytochrome oxydase I, COI) and one nuclear gene (RAG1) to examine relationships with the hypothesized closest relatives $P$. antisuyu Catenazzi \& Lehr, 2018, P. cruciocularis Lehr, Lundberg, Aguilar \& von May, 2006, and P. erythroinguinis Catenazzi \& Lehr, 2018, as well as related species of the P. llojsintuta Köhler \& Lötters, 1999 - P. platydactylus Boulenger, 1903 complex. We extracted DNA from tissues of the holotype, CORBIDI 14430 by using a commercial extraction kit (IBI Scientific, Peosta, USA). We followed standard protocols for amplification and sequencing of DNA (Hedges et al. 2008; Catenazzi and Ttito 2016). We used the 16Sar forward (5'-3' sequence: CGCCTGTTTATCAAAAACAT) and $16 \mathrm{Sbr}$ reverse (5'-3' sequence: CCGGTCTGAACTCAGATCACGT) primers for 16S, the Chmf4 forward (TYTCWACWAAYCAYAAAGAYATCGG) and Chmr4 reverse (ACYTCRGGRTGRCCRAARAATCA) primers for COI, and the R182 forward (GCCATAACTGCTGGAGCATYAT) and R270 reverse (AGYAGATGTTGCCTGGGTCTTC) primers for RAG1 (Palumbi et al. 2002; von May et al. 2017). We used the following thermocycling conditions during the polymerase chain reaction (PCR) with a ProFlex thermal cycler (Applied Biosystems): one cycle of $96^{\circ} \mathrm{C} / 3 \mathrm{~min} ; 35 \mathrm{cy}-$ cles of $95{ }^{\circ} \mathrm{C} / 30 \mathrm{~s}, 55^{\circ} \mathrm{C} / 45 \mathrm{~s}, 72{ }^{\circ} \mathrm{C} / 1.5 \mathrm{~min}$; one cycle $72{ }^{\circ} \mathrm{C} / 7 \mathrm{~min}$. We purified PCR products with Exosap-IT (Affymetrix, Santa Clara, CA) and shipped the purified products to MCLAB (San Francisco, CA) for sequencing. Newly generated sequences were deposited in GenBank (Suppl. material 2).
We downloaded sequences of closely related (on the basis of BLAST results for 16S) or morphologically similar, congeneric species and of two species of Oreobates (used as outgroup taxa) from GenBank (Suppl. material 2). We used Geneious R11, version 11.1.5 (Biomatters, http://www.geneious.com/) to assemble pairend reads, to generate a consensus sequence, to align our novel and GenBank sequences with the alignment program MAFFT v7.017 (Katoh and Standley 2013), and also to concatenate sequences of the three genes. We trimmed aligned sequences to a length of $571 \mathrm{bp}$ for 16S, 678 for COI, and 645 bp for RAG1 (total length $1894 \mathrm{bp}$ ), after removing regions of ambiguous alignment for $16 \mathrm{~S}$. Our analysis included 56 terminals. We used PartitionFinder, v. 1.1.1 to select the best partitioning scheme and substitution model for each gene using the Bayesian information criterion (BIC). The best partitioning scheme included six partitions: subset 1 for $16 \mathrm{~S}$ with the model GTR $+\mathrm{I}+\mathrm{G}$, subset 2 for the first codon position of COI with $\mathrm{SYM}+\mathrm{I}+\mathrm{G}$, subset 3 for the second codon position of COI with TVM + I, subset 4 for the third codon position of COI with TIM $+\mathrm{G}$, subset 5 for the first and second codon positions of RAG1 with $\mathrm{HKY}+\mathrm{G}$, and subset 6 with the third codon positions of RAG1 with $\mathrm{K} 81+\mathrm{G}$.

We inferred phylogenetic relationships with Maximum Likelihood (ML) inference. We conducted the analysis with IQ-TREE v1.6.12 (Nguyen et al. 2015) using our concatenated dataset, the partitioning and substitution models determined by PartitionFinder, and the ultrafast bootstrap method (10000 bootstrap alignments). We also estimated genetic distances for the $16 \mathrm{~S}$ rRNA mitochondrial fragment to provide further support of species delimitation. Although there is not a set threshold for delimiting species, Fouquet et al. (2007) suggested that $3 \%$ distance for $16 \mathrm{~S}$ is a reasonable criterion to identify putative new species. The benefit of using $16 \mathrm{~S}$ is that this fragment is the most frequently sequenced marker for anuran taxonomy (Fouquet et al. 2007; Padial et al. 2009; Vences et al. 2005), including for species of Holoadeninae (Hedges, Duellman \& Heinicke, 2008). We estimated uncorrected p-distances (i.e., the proportion of nucleotide sites at which any two sequences are different) with the R package "ape" (Paradis et al. 2004), and uploaded the table to Figshare (https://doi.org/10.6084/ m9.figshare.13640615).

The electronic version of this article in portable document format will represent a published work according to the International Commission on Zoological Nomenclature (ICZN), and hence the new names contained in the electronic version are published under that Code from the electronic edition alone. This published work and the nomenclatural acts it contains have been registered in ZooBank, the online registration system for the ICZN. The ZooBank LSIDs (Life Science Identifiers) and the associated information can be viewed through any standard web browser at http://zoobank.org/117AA0B4-99A24F4F-85A9-B9FAE8E47BB1. 


\section{Results}

\section{Generic placement}

Our study (Figure 1) supports the generic placement of the new species and its distinctiveness with respect to similar species. According to phylogenetic analyses, the closest related species are P. antisuyu Catenazzi and Lehr 2018, P. cruciocularis Lehr, Lundberg, Aguilar, von May 2006, and P. erythroinguinis Catenazzi and Lehr 2018. These four species form a well-supported clade of mostly Andean foothill and montane forest small Pristimantis with cruciform eyes and, except for P. sira sp. nov., yellow or red coloration on groin and belly. The close relationships among $P$. antisuyu, P. cruciocularis, P. erythroinguinis and $P$. sira sp. nov. are supported by $16 \mathrm{~S}$ rRNA genetic distances (Figshare https://doi.org/10.6084/ m9.figshare.13640615), which are smallest for pairwise comparisons among these four species (range 7.2-10.2\%) than they are for comparisons with other species of Pristimantis (all distances $>10.2 \%$ ).

\section{Description}

\section{Pristimantis sira sp. nov.}

http://zoobank.org/6579CBED-1CF0-4D59-8B37-FDB405EFB352

Figs $1-3,4 \mathrm{D}$

Holotype. PERU • 1 †, adult; Huánuco department, Huánuco province, Campamento Peligroso, El Sira Communal reserve; 925'34.2"S, 74²4'6.6"W; 1520 m a.s.1.; 24 March 2014; G. Chávez and Jose Malqui; CORBIDI 14430.

Paratopotypes. PERU $\bullet 1 \hat{\sigma}, 2$, adults and a juvenile; same data as for holotype; 01 December 2013; G. Chávez; CORBIDI 14433 (Figure 3C, D), 14429 (Figure 3E, F), 14432, 13952.

Paratypes. PERU 1 을 adult and a juvenile; Huánuco department, Pachitea province, Campamento La Cumbre; $9^{\circ} 25^{\prime} 27.0^{\prime \prime S}, 74^{\circ} 42^{\prime} 47.0^{\prime \prime} \mathrm{W} ; 2145 \mathrm{~m}$ a.s.1.; 30 November 2013; G. Chávez; CORBIDI 13933, 13944.

Diagnosis. The new species is diagnosed by the following combination of characters: (1) skin on dorsum finely shagreen with a few scattered subconical tubercles, that on venter areolate, W-shaped scapular fold present, discoidal fold absent, dorsolateral folds absent; (2) tympanic membrane and tympanic annulus absent, supratympanic fold absent; (3) snout acutely rounded from dorsal view, moderate in length and rounded from lateral view, canthus rostralis weakly concave in dorsal view, angular in lateral view, loreal region concave, rostral papilla or keel absent; (4) upper eyelid bearing two or three sub conical small tubercles, narrower than IOD, cranial crests absent; (5) dentigerous process of vomers absent; (6) males with vocal sacs and vocal slits, nuptial excrescences absent; (7) heels lacking tubercles; (8) finger I shorter than finger II, tips of digits expanded, bearing circumferential grooves, discs about 1.5 times wider than digits in fingers I, II and III, finger IV bearing a rounded disc about twice as wide as its digit; (9) fingers with narrow lateral fringes; (10) antebrachial tubercle absent; (11) ulnar and tarsal tubercles absent (12) inner metatarsal tubercle oval twice as long as round outer metatarsal tubercle, low supernumerary plantar tubercles at the base of toes II, III, IV and $\mathrm{V}$; (13) toes without lateral fringes, webbing absent, toe V longer than toe III; (14) in life, dorsum yellowish-brown, dark brown or olive brown with dark transversal bands; interorbital bar dark brown; canthus rostralis paler than loreal region and dark bordered; dark labial bars present; throat, chest, and belly dark brown or dark grey with scattered white flecks; groins, posterior surfaces of thighs, and shanks dark brown; iris copper yellow with a vertical black line and dark reticulations, black pupil surrounded by a copper orange ring; (15) SVL 12.9-14.7 $\mathrm{mm}$ in males; $19.0-20.4 \mathrm{~mm}$ in females.

Comparisons. The combination of having a vertical line crossing the iris (which forms a cruciform mark) and lacking tympanic annulus and membrane distinguishes Pristimantis sira $\mathrm{sp}$. nov. from most congeners except P. altamazonicus Barbour \& Dunn, 1921, P. antisuyu, P. ashaninka Lehr Moravec, 2017, P. cruciocularis and P. erythroinguinis. However, P. sira is easily differentiable from all of them by (condition for the other species in parenthesis): having 2-3 small sub conical tubercles on upper eyelid (vs a single conical tubercle in P. altamazonicus, 4-6 small tubercles in $P$. antisuyu, enlarged conical tubercles in $P$. ashaninka, 2-5 small tubercles in P. cruciocularis, and 4-6 large and small tubercles in P. erythroinguinis), groins and posterior surface of thighs dark without spots or flecks (vs bearing red or yellow blotches in $P$. cruciocularis, yellow blotches in $P$. antisuyu, red blotches in P. erythroinguinis, see Figure 4), vocal slits in males (vs absent in P. altamazonicus, P. antisuyu, P. cruciocularis and $P$. erythroinguinis), vomerine teeth absent (vs present in P. altamazonicus, P. antisuyu, P. ashaninka, P. cruciocularis and P. erythroinguinis), and heels lacking tubercles (vs present P. altamazonicus, P. antisuyu, $P$. ashaninka, P. cruciocularis and $P$. erythroinguinis). Additionally, $P$. sira is genetically related to $P$. croceoinguinis Lynch, 1968, and P. boucephalus Lehr, Moravec, Cusi, Gvozdik, 2017. Nevertheless, P. sira is distinct in bearing dark groins without blotches (vs yellow groin in $P$. croceoinguinis and P. boucephalus), skin on dorsum shagreen (vs tuberculate in $P$. croceoinguinis and smooth in $P$. boucephalus), upper eyelid having two or three sub conical tubercles (vs tubercles absent in P. creoceoinguinis), lacking dentigerous process of vomers (vs present in $P$. croceoinguinis), and heels lacking tubercles (vs conical tubercle on heels present in $P$. boucephalus).

Description of the holotype. An adult female (CORBIDI 14430; Figure 2A-E, 3A, B) with a SVL of $19.6 \mathrm{~mm}$, head as wide as long (Fig. 2A, B); snout acutely rounded in dorsal view and rounded in lateral view, short (eyenostril distance $9.8 \%$ of SVL); canthus rostralis distinct in lateral view; loreal region concave; nostrils protuberant, 

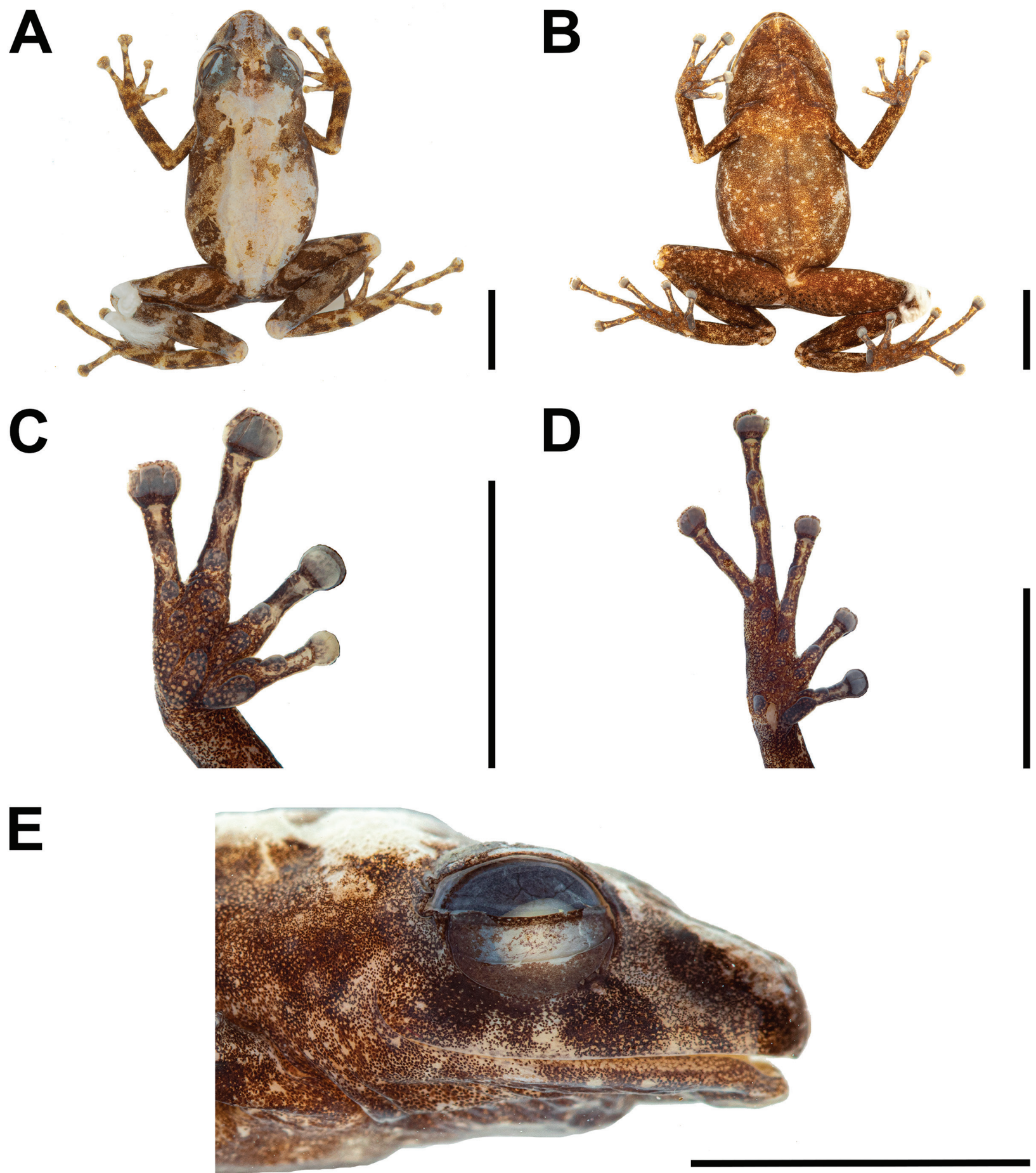

Figure 2. Holotype of Pristimantis sira sp. nov. in preservative (CORBIDI 14430). (A) dorsal view of the body; (B) ventral view of the body; (C) ventral view of the right hand; (D) ventral view of the right foot; (E) lateral view of the head. Photographs by Luis A. García-Ayachi. Scale bar $=5 \mathrm{~mm}$.

directed anteriorly; interorbital area flat, slightly broader than upper eyelid (upper eyelid width $89 \%$ of interorbital distance); cranial crests absent; upper eyelid bearing two small subconical tubercles; tympanic membrane absent; tympanic annulus absent (Fig. 2E); postrictal tubercles absent. Choanae small, rounded, not concealed by palatal shelf of maxillary; tongue longer than wide and granular, dentigerous processes of vomers absent. Skin texture on dorsum and flanks finely shagreen; dorsolateral folds absent; venter areolate; thoracic fold present, discoidal fold absent, cloacal sheath absent. Forearm slender; ulnar tubercles absent, ulnar fold absent; radio-ulnar length $22 \%$ of SVL; fingers with narrow lateral fringes; relative lengths of fingers I $\leq$ II $<$ IV $<$ III; palmar tubercle bilobed, thenar tubercle oval (Fig. 2C); subarticular tubercles round, prominent; supernumerary palmar tubercles 


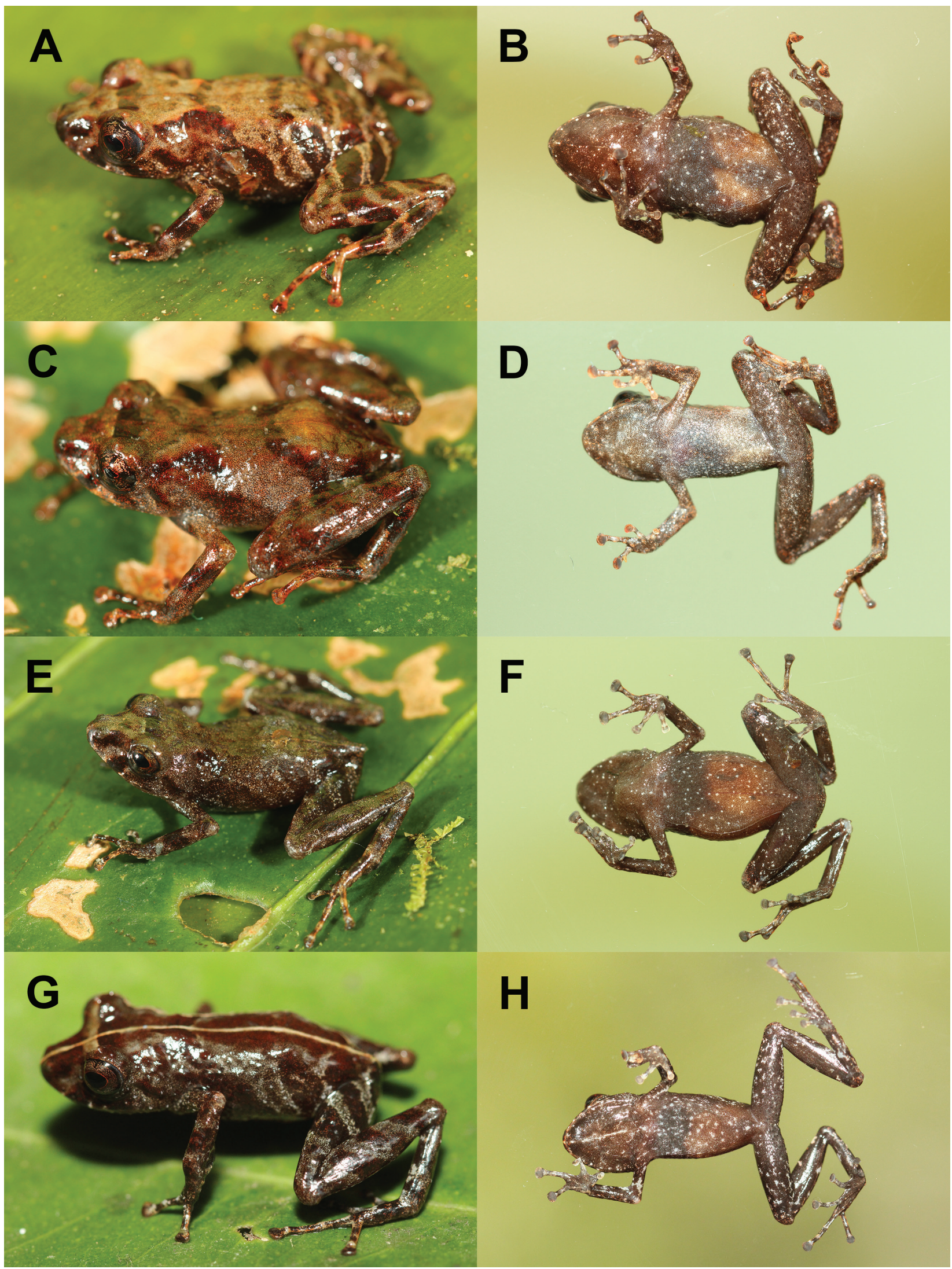

Figure 3. Coloration in life of the type series of Pristimantis sira sp. nov.: (A, B) adult female (CORBIDI 14430, holotype); (C, D) adult male (CORBIDI 14433); (E, F) adult female (CORBIDI 14429); (G, H) juvenile male (CORBIDI 13952). Photographs by Germán Chávez. 


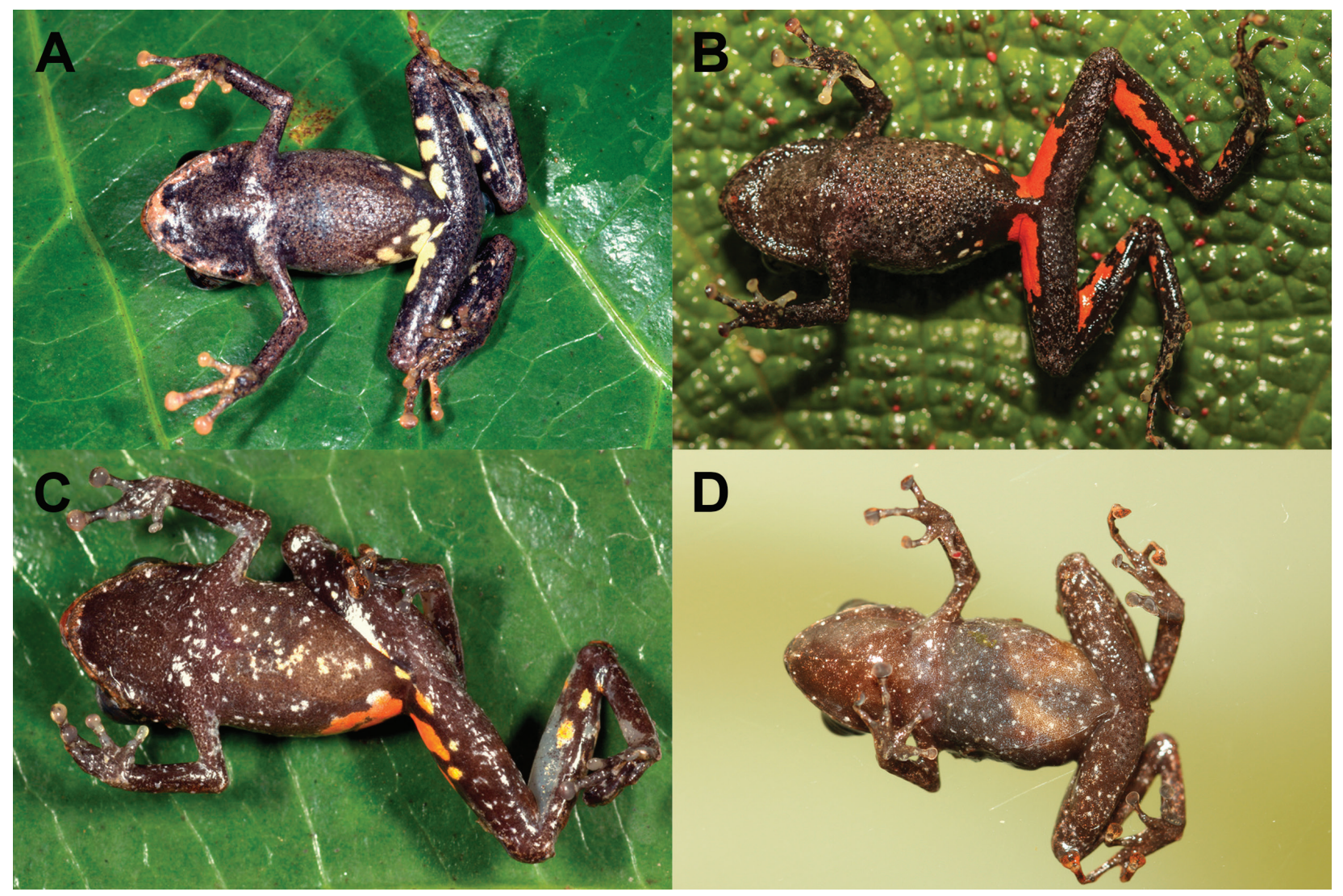

Figure 4. Ventral view in life of Pristimantis cruciocularis group's species: (A) P. antisuyu (CORBIDI 18726); (B) P. cruciocularis (CORBIDI 11554); (C) P. erythroinguinis (MUSM 30468); (D) P. sira sp. nov. (CORBIDI 14430). Photographs by Alessandro Catenazzi (A, C) and Germán Chávez (B, D).

present at the base of all fingers; disc cover finger I barely expanded, those of fingers III and IV extensively expanded (Fig. 2C), outer discs of fingers as wide as those of toes; discs covered with elliptical ventral pads defined by circummarginal grooves. Hind limbs slender; tibia length $48 \%$ of SVL; foot length $94 \%$ of tibia length; tarsal fold absent, tarsal tubercles absent; heel lacking tubercles; toes without lateral fringes; subarticular tubercles round, prominent; inner metatarsal tubercle oval, about 2.4 times the size of subconical outer tubercle (Fig. 2D); supernumerary plantar tubercles low at the base of all toes; discs covers slightly expanded; toes with defined pads; discs pads nearly elliptical; relative length of toes I $<$ II $<$ III $<\mathrm{V}<\mathrm{IV}$; tip of toe $\mathrm{V}$ reaching proximal border of distal subarticular tubercle IV; tip of toe II reaching proximal border of distal subarticular tubercle of Toe III (Fig. 2D).

Measurements (in $\mathrm{mm}$ ) and proportions of the holotype: $\mathrm{SVL}=19.6 ; \mathrm{HL}=6.7 ; \mathrm{HW}=7.2 ; \mathrm{ED}=2.7 ; \mathrm{E}-\mathrm{N}=$ $1.9 ; \mathrm{IOD}=1.8 ; \mathrm{EW}=1.6 ; \mathrm{IND}=1.7 ; \mathrm{TL}=9.5 ; \mathrm{FL}=9.0 ;$ $\mathrm{HL} / \mathrm{SVL}=0.3 ; \mathrm{HW} / \mathrm{SVL}=0.3 ; \mathrm{EW} / \mathrm{IOD}=0.8 ; \mathrm{E}-\mathrm{N} / \mathrm{ED}$ $=0.7 ; \mathrm{TL} / \mathrm{SVL}=0.4 ; \mathrm{FL} / \mathrm{SVL}=0.4 ; \mathrm{FL} / \mathrm{TL}=0.9$.

Coloration in life (Fig. 3A, B). Dorsum, flanks, and dorsal surface of limbs are yellowish-brown with dark brown transversal bands and reddish-orange tubercles; dorsal surface of head bearing a dark brown interorbital bar; canthus rostralis yellowish-brown, loreal region dark brown, labial bars dark brown, and white minute flecks present on the upper labial region. Throat, chest, belly, ventral surface of limbs, hands and feet dark brown with white flecks; groins, posterior surface of thighs, and posterior surface of shanks dark brown. Anterior surface of thighs is dark brown. Iris copper yellow with a vertical black line and dark reticulations, black pupil surrounded by a copper orange ring.

Coloration in preservative (Fig. 2A, B). Despite the skin on dorsum suffering damage, the coloration is similar to coloration in life, except that dark brown coloration turned yellowish-brown. The venter, limbs and ventral surfaces of hands and feet are yellowish-brown with creamy-white flecks, discs on hands and feet dark grey; iris gray.

Intraspecific variation. Dorsal coloration from yellowish brown to dark brown in juvenile CORBIDI 13952 (Figure $3 \mathrm{G}, \mathrm{H}$ ) and olive brown in female CORBIDI 14429 (Figure 3E, F). Moreover, CORBIDI 13952 has a pattern consisting of a middorsal creamy white line going from the tip of the nose to the cloaca, a pale interorbital bar, and a thin creamy white mid-throat line going from the chin to the distal edge of the throat. Furthermore, male CORBIDI 14433 (Figure 3C, D) has a yellowish-brown throat, a greyish-white belly, and yellowish-brown coloration on the ventral and posterior surface of thighs. Table 1 reports variation in measurements and proportions. 


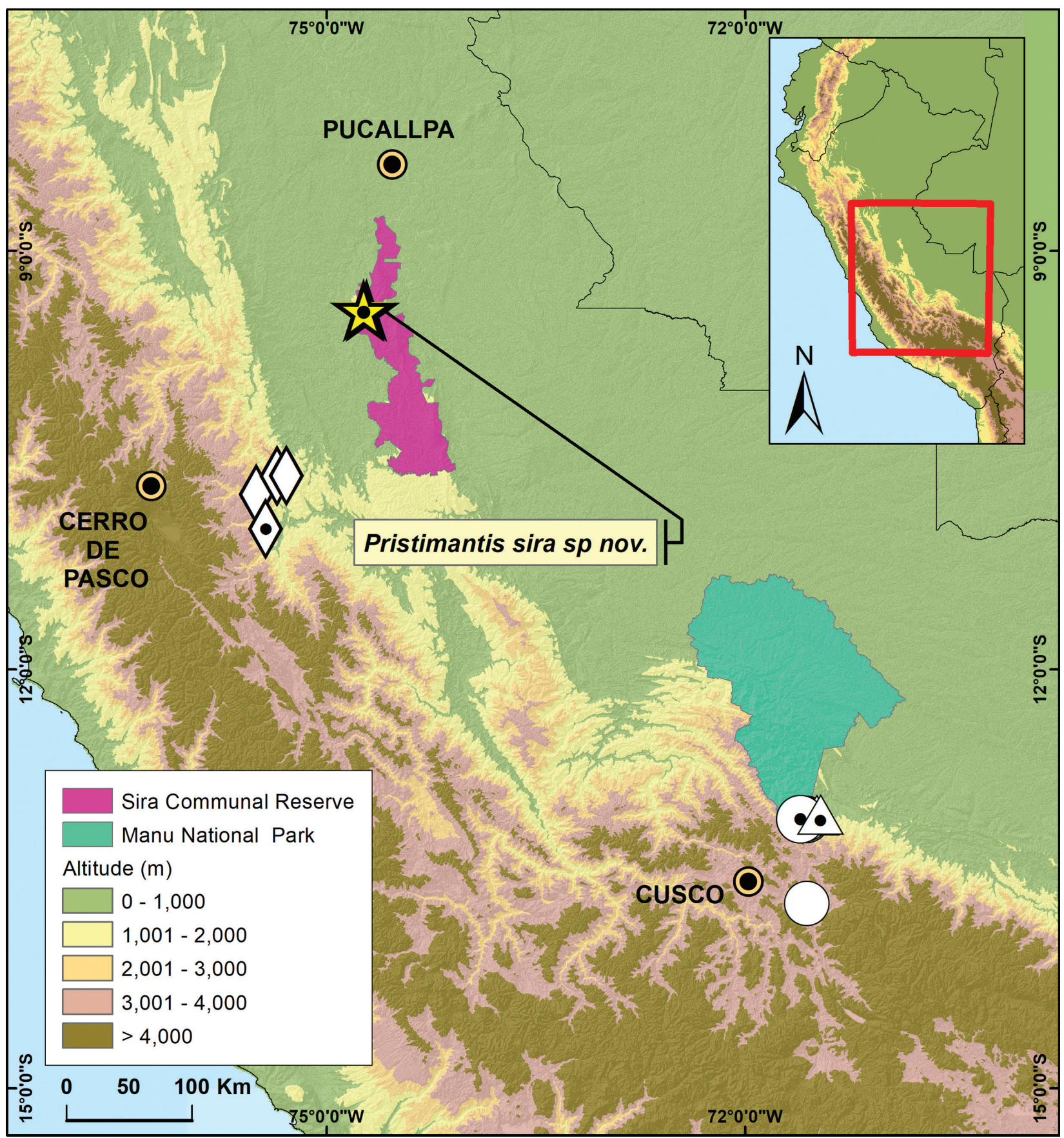

Figure 5. Map indicating the type locality of Pristimantis sira sp. nov. (yellow star), as well as type localities (symbols with a central black point) and distribution of the species of the P. cruciocularis group: P. antisuyu (white circles), P. cruciocularis (white rhomboids), P. erythroinguinis (white triangles).

Etymology. The species epithet "sira" is a noun in apposition, referencing El Sira Communal Reserve, a protected area established in 2001, containing the type locality of the new species. El Sira also protects one of the last large extensions of primary mountain forests in Central Peru.

Distribution, natural history and threats. We observed Pristimantis sira sp. nov. on leaves, at 1-1.7 m height, in the forests of the eastern slopes of the mountains of El Sira Communal Reserve, between 1500-
$2200 \mathrm{~m}$ a.s.l (Figure 5). The habitat at $1500 \mathrm{~m}$ a.s.l. is a montane forest, with riparian vegetation consisting mainly of bushes, tree ferns and trees canopy $\sim 20 \mathrm{~m}$ tall (Figure 6A, C). Climbers are also present (lianas) as well as low epiphytes, ferns, mushrooms, and lichens on the ground. Low trees (no more than 8-10 m tall) dominate the forest at $2000 \mathrm{~m}$ a.s.l. (Figure 6B), where there are bushes and large patches of Chusquea spp., in addition to small ferns, epiphytes and mushroom colonies. We found $P$. sira at night, at the beginning and the end 

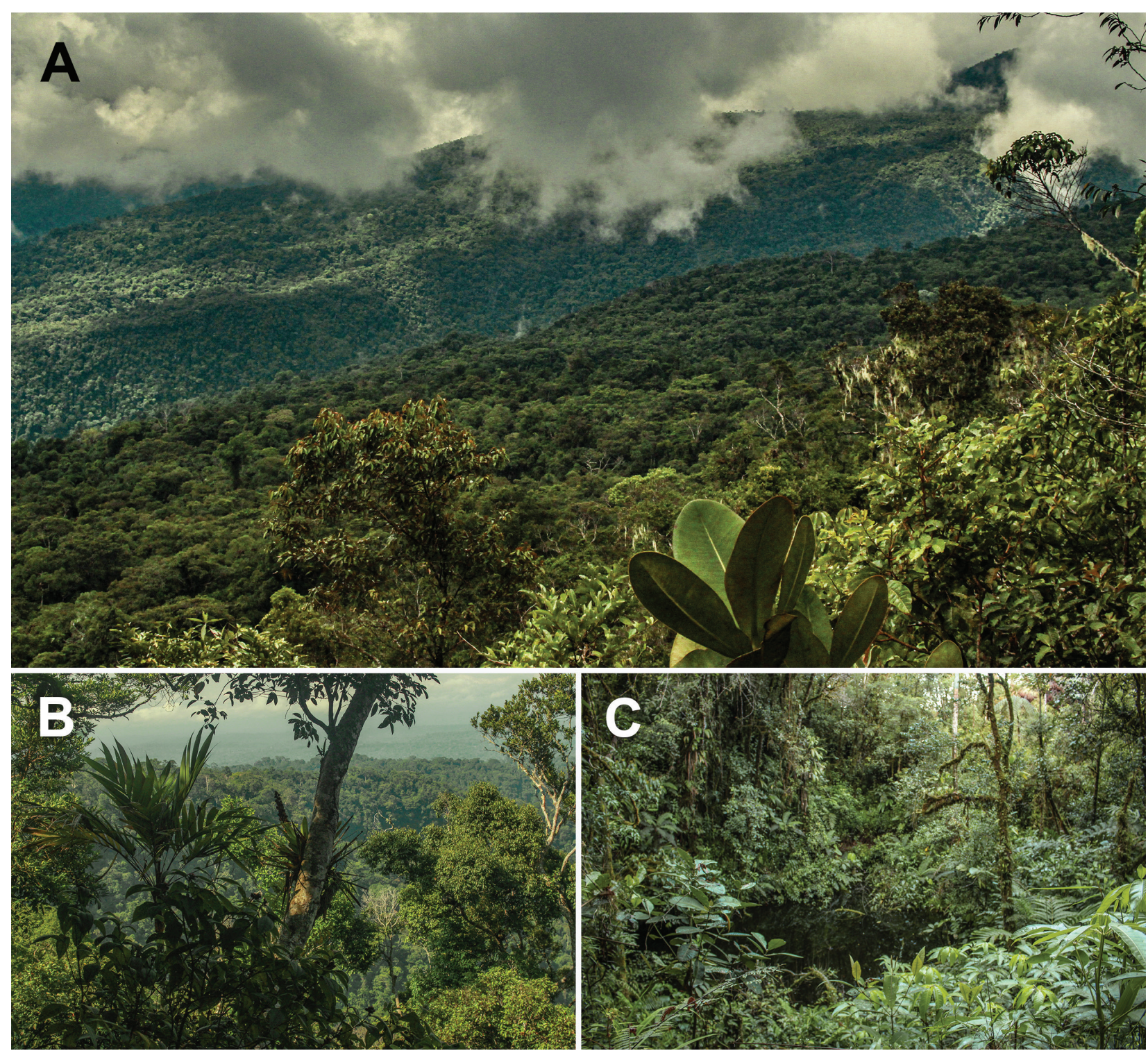

Figure 6. Habitat in the localities where Pristimantis sira sp. nov. occurs: (A) Panoramic view of the Montane forests in El Sira Communal Reserve; (B) forest in Campamento La Cumbre; (C) forest in Campamento Peligroso (type locality). Photographs by Germán Chávez.

Table 1. Range and average ( \pm standard deviation) measurements (in $\mathrm{mm}$ ) of specimens of the type series of Pristimantis sira sp. nov. and related cruciform eye's montane species of the Pristimantis cruciocularis group.

\begin{tabular}{|c|c|c|c|c|c|c|c|c|}
\hline & \multicolumn{2}{|c|}{ Pristimantis sira sp. nov. } & \multicolumn{2}{|c|}{ Pristimantis antisuyu } & \multicolumn{2}{|c|}{ Pristimantis cruciocularis } & \multicolumn{2}{|c|}{ Pristimantis erythroinguinis } \\
\hline & Females $(n=4)$ & $\begin{array}{l}\text { Males } \\
(\mathrm{n}=1)\end{array}$ & Females $(n=6)$ & $\begin{array}{l}\text { Males } \\
(\mathrm{n}=2)\end{array}$ & Females $(n=7)$ & Males $(n=7)$ & $\begin{array}{c}\text { Females } \\
(\mathrm{n}=2)\end{array}$ & Males $(n=4)$ \\
\hline SVL & $19.0-20.4(19.7 \pm 0.6)$ & 14.7 & $17.4-21.1(20.0 \pm 0.6)$ & $14.3-15.0$ & $18.7-21.8(20.3 \pm 1.2)$ & $11.4-15.4(13.5 \pm 1.2)$ & $17.2-17.7$ & $12.2-14.3(13.0 \pm 0.5)$ \\
\hline TL & $9.5-10.9(10.1 \pm 0.6)$ & 8.3 & $9.8-11.2(10.8 \pm 0.2)$ & $8.2-8.4$ & $9.6-11.1(10.5 \pm 0.6)$ & $6.2-8.0(7.2 \pm 0.6)$ & $9.4-9.5$ & $7.2-8.3(7.7 \pm 0.2)$ \\
\hline FL & $8.7-9.2(9.0 \pm 0.2)$ & 6.9 & $7.9-9.6(9.1 \pm 0.3)$ & $6.4-7.0$ & $7.5-8.6(7.8 \pm 0.5)$ & $4.6-6.5(5.6 \pm 0.6)$ & $7.4-7.8$ & $5.6-6.5(6.0 \pm 0.2)$ \\
\hline HL & $6.3-6.9(6.7 \pm 0.3)$ & 5.1 & $.9-8.2(7.8 \pm$ & $6.1-6.2$ & $6.9-7.9(7.4 \pm 0.3)$ & $4.6-6.6(5.2 \pm 0.7)$ & $6.7-7.9$ & $5.2-6.0(5.7 \pm 0.2)$ \\
\hline HW & $7.2-7.5($ & 5.4 & $6.4-8.0(7$ & $5.4-5.6$ & $7.1-8.0(7.6 \pm$ & $4.7-5.8(5.0 \pm 0.4)$ & $5.9-7.0$ & $4.7-5.7(5.0 \pm 0.2)$ \\
\hline ED & $2.3-2.8$ & 2.0 & $2.4-2.9(2.7 \pm$ & $2.2-2.3$ & $2.5-2.9(2.7=$ & $1.5-2.4($ & $2.5-2.8$ & $2.0-2.1(2.0 \pm 0)$ \\
\hline IOD & $1.8-2.0(1.9 \pm 0.1)$ & 1.7 & $2.3-2.6(2$ & $1.8-1.9$ & $2.7-2.9(2.8 \pm$ & $1.5-2.2(1.9 \pm 0.2)$ & 1.8 & $1.4-1.9(1.7 \pm 0.1)$ \\
\hline EW & $1.6-2.0(1.8 \pm 0.1)$ & 1.6 & $1.8-2.2(2.0 \pm 0.1)$ & $1.4-1.8$ & $1.4-2.0(1.6 \pm$ & $1.2-1.5(1.3 \pm 0.1)$ & $1.8-1.9$ & $1.3-1.7(1.6 \pm 0.1)$ \\
\hline IND & $1.7-1.8(1.8 \pm 0.1)$ & 1.4 & $1.4-1.9(1.6 \pm 0.1)$ & 1.3 & $1.6-2.0(1.8=$ & $1.1-1.4$ & $1.3-1.5$ & $0.9-1.2(1.1 \pm 0.1)$ \\
\hline E-N & $1.9-2.1(2.0 \pm 0.1)$ & 1.5 & $1.9-2.3(2.2 \pm 0.1)$ & 1.9 & $1.9-2.4(2.1 \pm 0.2)$ & $1.4-2.2(1.7 \pm 0.3)$ & $1.7-2.0$ & $1.3-1.5(1.4 \pm 0.1)$ \\
\hline TL/SVL & $0.48-0.57(0.52 \pm 0.04)$ & 0.56 & $.53-0.56(0.54 \pm 0.01)$ & $0.56-0.57$ & $0.50-0.54(0.52 \pm 0.02)$ & $0.52-0.55(0.54 \pm 0.01)$ & $0.53-0.55$ & $0.57-0.61(0.59 \pm 0.01)$ \\
\hline FL/SVL & $0.44-0.47(0.45 \pm 0.01)$ & 0.47 & $0.44-0.47(0.45 \pm 0.01)$ & $0.45-0.47$ & $0.37-0.40(0.38 \pm 0.01)$ & $0.40-0.42(0.41 \pm 0.01)$ & $0.42-0.45$ & $0.45-0.46(0.46 \pm 0)$ \\
\hline HL/SVL & $0.32-0.35(0.34 \pm 0.01)$ & 0.34 & $0.37-0.41(0.39 \pm 0.00)$ & $0.41-0.43$ & $0.33-0.41(0.37 \pm 0.03)$ & $0.36-0.43(0.39 \pm 0.03)$ & $0.38-0.46$ & $0.42-0.46(0.44 \pm 0.01)$ \\
\hline HW/SVL & $0.37-0.39(0.38 \pm 0.01)$ & 0.37 & $0.34-0.38(0.36 \pm 0.01)$ & $0.36-0.39$ & $0.35-0.40(0.37 \pm 0.01)$ & $0.35-0.41(0.37 \pm 0.02)$ & $0.33-0.41$ & $0.37-0.40(0.38 \pm 0.01)$ \\
\hline HW/HL & $1.06-1.19(1.11 \pm 0.05)$ & 1.07 & $0.87-0.98(0.93 \pm 0.02)$ & $0.89-0.90$ & $0.97-1.06(1.03 \pm 0.03)$ & $0.87-1.02(0.97 \pm 0.07)$ & $0.88-0.89$ & $0.81-0.95(0.87 \pm 0.03)$ \\
\hline E-N/ED & $0.70-0.84(0.79 \pm 0.07)$ & 0.77 & $0.76-0.82(0.79 \pm 0.01)$ & $0.83-0.86$ & $0.68-0.85(0.79 \pm 0.07)$ & $0.74-1.00(0.88 \pm 0.11)$ & $0.68-0.71$ & $0.62-0.75(0.67 \pm 0.03)$ \\
\hline EW/IOD & $0.89-1.00(0.93 \pm 0.05)$ & 0.97 & $0.75-0.88(0.82 \pm 0.02)$ & $0.74-1.00$ & $0.48-0.74(0.59 \pm 0.10)$ & $0.55-0.80(0.67 \pm 0.09)$ & $1.00-1.06$ & $0.89-1.00(0.94 \pm 0.02)$ \\
\hline
\end{tabular}


of the rainy season, but could not hear any male calling. Sympatric species were Pristimantis cruciocularis, $P$. iiap Padial, Gagliardi-Urrutia, Chaparro \& Gutiérrez, 2016, P. cf. mendax Duellman, 1978, and Rhinella nesiotes Duellman \& Toft, 1979. We have noticed illegal mining activity in the foothills of El Sira Communal Reserve. Mining activities could affect the mountain slopes because miners establish camps and build trails to move their equipment across the watersheds, creating disturbance to stream and riverine environments that could cause further deforestation in the type locality of P. sira.

\section{Discussion}

Previous genetic analyses have shown that a group of Pristimantis frogs characterized by cruciform eyes are closely related, and include $P$. antisuyu, $P$. cruciocularis, and $P$ erythroinguinis (Catenazzi and Lehr 2018). Our study suggests that $P$. sira sp. nov. belongs to the same group. Likewise, these species are forming a clade into the larger P. platydactylus - P. llojsintuta complex (Padial et al. 2009) (see Figure 1). We propose to name the clade "Pristimantis cruciocularis group" following Article 61 (Principle of typification) of the International Code of Zoological Nomenclature 1999, which recommends using the oldest bearing-type species belonging within the defined taxonomic boundaries of the group. Additionally, the cruciform eye is a character present in two other species that are not closely related to the $P$. cruciocularis group: $P$. ashaninka and $P$. altamazonicus. Pristimantis ashaninka inhabits mountain forests, whereas $P$. altamazonicus is an Amazon lowlands dweller. Our phylogenetic analyses suggest that $P$. ashaninka is not closely related to $P$. sira (but only $16 \mathrm{~S}$ rRNA fragments are available for $P$. ashaninka). Further analyses and gene sampling are necessary to confirm the relationships of montane species with cruciform eye.

We compared measurements and proportions of $P$. antisuyu, P. cruciocularis, and P. erythroinguinis, all montane species morphologically similar to $P$. sira (Table 1), concluding that they appear very similar in measurements. We also realised that proportions published in the table 3 of the original description of P. cruciocularis (Lehr et al. 2006) seem to be incorrect: males proportions correspond to females and viceversa. Thus, in order to help future research and publish confident morphological data, we present a new measurement dataset of $P$. cruciocularis, including populations formerly assigned to $P$. flavobracatus Lehr, Lundberg, Aguilar \& von May, 2006, a junior synonym of $P$. cruciocularis sensu Catenazzi and Lehr (2018).

We have observed illegal gold mining activity near the type locality of $P$. sira sp. nov. Gold mining involves the establishment of mining camps and the subsequent clearing of big areas, which would affect the habitat of the new species. Following the IUCN criteria, and considering the aforementioned threat and that $P$. sira has been recorded in only two localities with a possible EOO not wider than $6000 \mathrm{~km}^{2}$ (which is the entire extension of the El Sira Communal Reserve, SERNANP 2020), we suggest this species to be placed into the Vulnerable category of the IUCN red list.

\section{Acknowledgements}

This research would not have been possible without the valuable support of the Deutsche Gesellschaft für Internationale Zusammenarbeit (GIZ) that trusted GC to perform the fieldwork. We are deeply grateful with Servicio Nacional de Áreas Naturales Protegidas (SERNANP) staff who made our work inside El Sira Communal Reserve possible. GC is very pleased to have shared the fieldwork with his friend Jose Malqui, who helped collect the type series of the new species. We also thank Milagros Toala and Katherine Toepfer for their valuable help with fieldwork arrangements.

\section{References}

Aichinger M (1991) A new species of Poison-dart frog (Anura: Dendrobatidae) from the Serranía de Sira, Peru. Herpetologica 47: 1-5.

Barbour T, Dunn ER (1921) Herpetological novelties. Proceedings of the Biological Society of Washington 34: 157-162.

Blackburn DC, Wake DB (2011) Class Amphibia Gray, 1825. In: Zhang Z-Q (Ed.) Animal biodiversity: an outline of higher-level classification and survey of taxonomic richness. Zootaxa 3148: 38-54. https://doi.org/10.11646/zootaxa.3148.1.8

Boulenger GA (1903) Descriptions of new batrachians in the British Museum. Annals and Magazine of Natural History 12: 552-557. https://doi.org/10.1080/00222930308678892

Catenazzi A, Ttito A (2016) A new species of Psychrophrynella (Amphibia, Anura, Craugastoridae) from the humid montane forests of Cusco, eastern slopes of the Peruvian Andes. PeerJ 4: e1807. https:// doi.org/10.7717/peerj.1807

Catenazzi A, Lehr E (2018) Pristimantis antisuyu sp. n. and Pristimantis erythroinguinis sp. n., two new species of terrestrial-breeding frogs (Anura, Strabomantidae) from the eastern slopes of the Andes in Manu National Park, Peru. Zootaxa 4394: 185-206. https://doi. org/10.11646/zootaxa.4394.2.2

Catenazzi A, Uscapi V, von May R (2015) A new species of Noblella (Amphibia, Anura, Craugastoridae) from the humid montane forests of Cusco, Peru. Zookeys 516: 71-84. https://doi.org/10.3897/zookeys.516.9776

Chávez G, Catenazzi A (2016) A new species of frog of the genus Pristimantis from Tingo Maria National Park, Huanuco Department, central Peru (Anura, Craugastoridae). Zookeys 610: 113-130. https:// doi.org/10.3897/zookeys.610.8507

Chávez G, Catenazzi A, Venegas PJ (2017) A new species of arboreal microteiid lizard of the genus Euspondylus (Gymnophtalmidae: Cercosaurinae) from the Andean slopes of central Peru with comments on Peruvian Euspondylus. Zootaxa 4350: 301-316. https:// doi.org/10.11646/zootaxa.4350.2.6 
Crump ML, Scott Jr NJ (1994) Visual encounter surveys. In: Heyer WR, Donnelly MA, McDiarmid RW, Hayek LC, Foster MS (Eds) Measuring and Monitoring Biological Diversity: Standard Methods for Amphibians. Smithsonian Institution, Washington DC, 84-92.

Duellman WE (1978) Three new species of Eleutherodactylus from Amazonian Perú (Amphibia: Anura: Leptodactylidae). Herpetologica 34: 264-270.

Duellman WE, Toft CA (1979) Anurans from Serranía de Sira, Amazonian Perú: Taxonomy and Biogeography. Herpetologica 35: 60-70.

Duellman WE, Lehr E (2009) Terrestrial Breeding Frogs (Strabomantidae) in Peru. Natur und Tier - Verlag GmbH, Germany, 384 pp.

Duellman WE, Barley AJ, Venegas PJ (2014) Cryptic species diversity in Marsupial Frogs (Anura: Hemiphractidae: Gastrotheca) in the Andes of Northern Peru. Zootaxa 3768: 159-177. https://doi. org/10.11646/zootaxa.3768.2.4

Echevarria LY, Venegas PJ (2015) A new elusive species of Petracola (Squamata: Gymnophthalmidae) from the Utcubamba basin in the Andes of Northern Peru. Amphibian \& Reptile Conservation 9: 26-33.

Fouquet A, Gilles A, Vences M, Marty C, Blanc M, Gemmell NJ (2007) Underestimation of species richness in Neotropical frogs revealed by mtDNA analyses. PLoS ONE 2: e1109. https://doi.org/10.1371/ journal.pone.0001109

Gagliardi-Urrutia G (2010) Anfibios y Reptiles de Loreto, Peru. The Field Museum-Rapid Color Guide \# 262.

Hedges SB, Duellman WE, Heinicke MP (2008) New World direct-developing frogs (Anura: Terrarana): Molecular phylogeny, classification, biogeography, and conservation. Zootaxa 1737: 1-182. https:// doi.org/10.11646/zootaxa.1737.1.1

Heinicke MP, Duellman WE, Hedges SB (2007) Major Caribbean and Central American frog faunas originated by ancient oceanic dispersal. Proceedings of the National Academies of Sciences 104: 1009210097. https://doi.org/10.1073/pnas.0611051104

Jiménez de la Espada M (1870) Fauna neotropicalis species quaedam nondum cognitae. Jornal de Sciências, Mathemáticas, Physicas e Naturaes. Lisboa 3: 57-65.

Katoh K, Standley DM (2013) MAFFT multiple sequence alignment software version 7: improvements in performance and usability. Molecular biology and evolution 30: 772-780. https://doi.org/10.1093/ $\mathrm{molbev} / \mathrm{mst} 010$

Köhler J, Lötters S (1999) New species of the Eleutherodactylus unistrigatus group (Amphibia: Anura: Leptodactylidae) from montane rain forest of Bolivia. Copeia 1999: 422-427. https://doi. org/10.2307/1447487

Lanfear R, Calcott B, Ho SYW, Guindon S (2012) Partitionfinder: combined selection of partitioning schemes and substitution models for phylogenetic analyses. Molecular biology and evolution 29: 16951701. https://doi.org/10.1093/molbev/mss020

Lehr E, Moravec J (2017) A new species of Pristimantis (Amphibia, Anura, Craugastoridae) from a montane forest of the Pui Pui Protected Forest in central Peru (Región Junín). Zookeys 645: 85-102. https://doi.org/10.3897/zookeys.645.11221

Lehr E, von May R (2017) A new species of terrestrial-breeding frog (Amphibia, Craugastoridae, Pristimantis) from high elevations of the Pui Pui Protected Forest in central Peru. Zookeys 660: 17-42. https://doi.org/10.3897/zookeys.660.11394

Lehr E, Lundberg M, Aguilar C, von May R (2006) New species of Eleutherodactylus (Anura: Leptodactylidae) from the eastern Andes of central Peru with comments on central Peruvian
Eleutherodactylus. Herpetological monographs 20: 105-128. https:// doi.org/10.1655/0733-1347(2007)20[105:NSOEAL]2.0.CO;2

Lehr E, von May R, Moravec J, Cusi JC (2017a) A new species of Phrynopus (Amphibia, Anura, Craugastoridae) from upper montane forests and high Andean grasslands of the Pui Pui Protected Forest in central Peru. Zookeys 713: 131-157. https://doi.org/10.3897/ zookeys.713.20776

Lehr E, von May R, Moravec J, Cusi JC (2017b) Three new species of Pristimantis (Amphibia, Anura, Craugastoridae) from Upper Montane Forests and High Andean Grasslands of the Pui Pui Protected Forest in Central Peru. Zootaxa 4299: 301-336. https://doi. org/10.11646/zootaxa.4299.3.1

Lehr E, Moravec J, Cusi JC, Gvozdik V (2017c) A new minute species of Pristimantis (Amphibia: Anura: Craugastoridae) with a large head from the Yanachaga-Chemillen National Park in central Peru, with comments on the phylogenetic diversity of Pristimantis occurring in the Cordillera Yanachaga. European Journal of Taxonomy 325: 1-22. https://doi.org/10.5852/ejt.2017.325

Lötters S, Henzl MJ (2000) A new species of Atelopus from the Serranía del Sira, Amazonian Peru. Journal of Herpetology 34: 169-173. https://doi.org/10.2307/1565411

Lynch JD (1968) Two new frogs of the genus Eleutherodactylus from Eastern Ecuador (Amphibia: Leptodactylidae). Journal of Herpetology 2: 129-135. https://doi.org/10.2307/1563112

Lynch JD, Duellman WE (1997) Frogs of the genus Eleutherodactylus (Leptodactylidae) in western Ecuador: Systematic, Ecology, and Biogeography. Natural History Museum, The University of Kansas, Lawrence, Kansas, 236 pp. https://doi.org/10.5962/bhl.title.7951

Nguyen LT, Schmidt HA, von Haeseler A, Minh BQ (2015) IQ-TREE: A fast and effective stochastic algorithm for estimating maximum-likelihood phylogenies. Molecular biology and evolution 32: 268-274. https://doi.org/10.1093/molbev/msu300

Padial JM, Grant T, Frost DR (2014) Molecular systematics of Terraranas (Anura: Brachycephaloidea) with an assessment of the effects of alignment and optimality criteria. Zootaxa 3825:1-132. https://doi. org/10.11646/zootaxa.3825.1.1

Padial JM, Gagliardi-Urrutia LAG, Chaparro JC, Gutiérrez RC (2016) A new species of the Pristimantis conspicillatus group from the Peruvian Amazon (Anura: Craugastoridae). Annals of the Carnegie Museum, Pittsburgh 83: 207-218. https://doi.org/10.2992/007.083.0302

Padial JM, Castroviejo-Fisher S, Köhler J, Vilá C, Chaparro JC, De la Riva I (2009) Deciphering the products of evolution at the species level: the need for an integrative taxonomy. Zoologica Scripta 38: 431-447. https://doi.org/10.1111/j.1463-6409.2008.00381.x

Palumbi S, Martin A, Romano S, McMilan WO, Stice L, Grabowski G (2002) Simple fool's guide to PCR: Version 2.0. Department of Zoology and Kewalo Marine Laboratory, University of Hawaii, 45 pp.

Paradis E, Claude J, Strimmer K (2004) APE: Analyses of Phylogenetics and Evolution in R language. Bioinformatics 20: 289-290. https://doi.org/10.1093/bioinformatics/btg412

SERNANP (2020) Servicio Nacional de Áreas Naturales Protegidas por el Estado. https://www.sernanp.gob.pe [accesed on 30.12.2020]

Shepack A, von May R, Ttito A, Catenazzi A (2016) A new species of Pristimantis (Amphibia, Anura, Craugastoridae) from the foothills of the Andes in Manu National Park, southeastern Peru. Zookeys 594: 143-164. https://doi.org/10.3897/zookeys.594.8295

Swenson JJ, Young BE, Beck S, Comer P, Córdova JH, Dyson J, Embert D, Encarnación F, Ferreira W, Franke I, Grossman D, Hernandez P, 
Herzog SK, Josse C, Navarro G, Pacheco V, Stein BA, Timaná M, Tovar A, Tovar C, Vargas J, Zambrana-Torrelio CM (2012) Plant and animal endemism in the eastern Andean slope: challenges to conservation. BMC Ecology 12: 1-1. https://doi.org/10.1186/1472-6785-12-1 von May R, Catenazzi A, Corl A, Santa-Cruz R, Carnaval AC, Moritz C (2017) Divergence of thermal physiological traits in terrestrial breeding frogs along a tropical elevational gradient. Ecology and Evolution 7: 3257-3267. https://doi.org/10.1002/ece3.2929

Vences M, Thomas M, Bonett R, Vieites D (2005) Deciphering amphibian diversity through DNA barcoding: chances and challenges. Philosophical Transactions of the Royal Society of London B 360: 1859-1868. https://doi.org/10.1098/rstb.2005.1717

Whitworth A, Beirne C, Pillco Huarcaya R, Serrano Rojas SJ, Chávez G (2016a) Amphibians of the Sira Communal Reserve. The Field Museum-Color Guide \# 809.

Whitworth A, Beirne C, Pillco Huarcaya R, Serrano Rojas SJ, Chávez G (2016b) Reptiles of the Sira Communal Reserve. The Field Museum-Color Guide \# 810

\section{Supplementary material 1}

\section{Material examined}

Authors: Germán Chávez, Luis A. García-Ayachi, Alessandro Catenazzi

Data type: species data

Copyright notice: This dataset is made available under the Open Database License (http://opendatacommons. org/licenses/odbl/1.0). The Open Database License $(\mathrm{ODbL})$ is a license agreement intended to allow users to freely share, modify, and use this Dataset while maintaining this same freedom for others, provided that the original source and author(s) are credited.

Link: https://doi.org/10.3897/evolsyst.5.63674.suppl1

\section{Supplementary material 2}

\section{Genbank accession codes for specimens considered for phylogenetic analyses.}

Authors: Germán Chávez, Luis A. García-Ayachi, Alessandro Catenazzi

Data type: molecular data

Copyright notice: This dataset is made available under the Open Database License (http://opendatacommons.org/licenses/odbl/1.0). The Open Database License $(\mathrm{ODbL})$ is a license agreement intended to allow users to freely share, modify, and use this Dataset while maintaining this same freedom for others, provided that the original source and author(s) are credited.

Link: https://doi.org/10.3897/evolsyst.5.63674.suppl2

\section{Supplementary material 3}

\section{Figure S1}

Authors: Germán Chávez, Luis A. García-Ayachi, Alessandro Catenazzi

Data type: image

Copyright notice: This dataset is made available under the Open Database License (http://opendatacommons.org/licenses/odbl/1.0). The Open Database License $(\mathrm{ODbL})$ is a license agreement intended to allow users to freely share, modify, and use this Dataset while maintaining this same freedom for others, provided that the original source and author(s) are credited.

Link: https://doi.org/10.3897/evolsyst.5.63674.suppl3 